\title{
Gene expression of resistin in adipose tissue and mammary gland of lactating and non-lactating cows
}

\author{
Tokushi Komatsu, Fumiaki Itoh, Satoshi Mikawa ${ }^{1}$ and \\ Koichi Hodate ${ }^{2}$ \\ Department of Animal Physiology and Nutrition, National Institute of Livestock and Grassland Science, Tsukuba Norindanchi, PO Box5, Ibaraki 305-0901, \\ Japan \\ ${ }^{1}$ National Institute of Agrobiological Science, Ibaraki, 305-8602, Japan \\ ${ }^{2}$ School of Veterinary Medicine and Animal Science, Kitasato University, Aomori 034-8628, Japan \\ (Requests for offprints should be addressed to T Komatsu; Email: koma2@affrc.go.jp)
}

\begin{abstract}
Resistin has been suggested to induce insulin resistance in obesity and to inhibit adipocyte differentiation. In lactating cows, glucose uptake in the mammary gland is a ratelimiting step in milk synthesis, and to supply glucose to the mammary gland, insulin resistance increases. We examined the expression of the resistin gene by real-time PCR of cDNA in the adipose tissue and mammary gland of lactating and non-lactating cows. Lactation induced a significant increase of resistin expression in adipose tissue compared with that in the dry period, and decreased resistin expression in the mammary gland. There were no significant differences in the expression of insulin responsive glucose transporter (GLUT4) mRNA between the adipose tissue of lactating and non-lactating cows, and
\end{abstract}

GLUT4 mRNA was not detected in the mammary gland. The plasma insulin concentration was lower in lactating cows than in non-lactating cows. These results indicate that the pattern of resistin expression in peripheral tissues is changed in association with milk production. The increase of resistin expression and maintenance of a lower level of plasma insulin concentration may decrease glucose availability by increasing insulin resistance in adipose tissue. Additionally, our results suggest that the decrease of resistin expression in the mammary gland may influence on the insulin-dependent glucose uptake in mammary epithelial cells during lactation.

Journal of Endocrinology (2003) 178, R1-R5

\section{Introduction}

Adipocytes secrete a number of molecules such as tumor necrosis factor- $\alpha$, leptin and adiponectin, thereby influencing the ability of the body to respond to insulin and glucose metabolism. Resistin was originally identified as an adipocyte-secreted factor overexpressed in murine models of obesity and downregulated by thiazolidinediones (TZDs), which are known to increase insulin sensitivity (Steppan et al. 2001). Administration of resistin impairs glucose tolerance and increases insulin resistance (Steppan et al. 2001). On the other hand, it has been reported that resistin gene expression was barely detectable in mature adipocytes, and that it was highly expressed in preadipocytes (Janke et al. 2002). Also, resistin expression is decreased in obese mice, and increases in ob/ob mice and Zucker diabetic fatty (ZDF) rats in response to PPAR $\gamma$ agonists (Way et al. 2001). However, in ruminants, whose sensitivity and response to insulin in peripheral tissues are much lower than those of humans (Rose et al. 1997), the sequence and expression of resistin have not been analyzed.

During lactation, the synthesis of lactose from glucose in the mammary epithelial cells seems to be the rate-limiting step in milk synthesis (Neville et al. 1983). In ruminants, the mammary gland cannot synthesize glucose from other precursors due to the lack of glucose 6-phosphatase (Threadgold et al. 1979). The milk yield increases at peak lactation because the supply of glucose to the mammary gland increases. It is considered that the increase in glucose supply is brought by increase of insulin resistance (McDowell et al. 1987), but the mechanism of the increase of insulin resistance during lactation is still unclear.

Since resistin has been suggested to inhibit insulin action and adipocyte differentiation in rodents, we 
expected that the expression of the resistin gene would change in lactation. In the present study, we assessed resistin and insulin responsive glucose tranporter (GLUT4) mRNA expression in adipose tissue and mammary gland, and the plasma insulin concentration in cows at during peak lactation and the dry period.

\section{Materials and Methods}

\section{Animals}

All animals received human care as outlined in the Guide for the Care and Use of Experimental Animals (National Institute of Livestock and Grassland Science). Four peak lactation ( 8 to 11 weeks after parturition) and four non-lactating (dried-off for 3 to 10 weeks) Holstein cows were fed according to the Japanese feeding standard, which was designed to meet the requirements for energy prior to slaughter. Tissues of visceral fat and mammary gland were collected immediately post-slaughter, frozen in liquid nitrogen, and stored at $-80{ }^{\circ} \mathrm{C}$ prior to RNA extraction.

\section{$R N A$ isolation and $c D N A$ synthesis}

Total RNA was extracted with TRIzol Reagent (Invitrogen, Leek, The Neterland) according to the manufacturer's protocol. cDNA was synthesized from $1-1000 \mathrm{ng}$ of total RNA using random hexamer (TaKaRa, Tokyo, Japan) and Murine Moloney leukemia virus reverse transcriptase (Gibco Life Technologies, Gaithersburg, MD).

\section{Design of RT-PCR primers for bovine resistin}

A BLAST search of the expressed sequence tag (EST) database with human resistin cDNA was performed to identify bovine ESTs encoding the resistin sequence. The bovine EST sequences were used to design the following RT-PCR primers for amplification of bovine resistin cDNA encoding the entire open reading frame: forward primer; 5'-AGTCCACAGAGAGGCACCTG3', reverse primer; 5'-GCGCAGTCTTAGGCTACT GG-3' and the following primers for real-time PCR of bovine resistin mRNA: forward primer; 5'-AGTCC ACAGAGAGGCACCTG-3', reverse primer; 5'-TG GTGACCTCCTGGATCTTC- ${ }^{\prime}$. The primers were located in different exons to allow discrimination of PCR products that might arise from possible chromosome DNA contaminants. The PCR products were analyzed by $2 \%$ agarose gel electrophoresis to confirm that only a DNA fragment of the predicted size was amplified. The PCR fragment was also sequenced with the ABI PRISM BigDye terminator system using an ABI PRISM 377 sequencer (Applied Biosystems, Foster city, CA, USA).
Real time PCR

Resistin gene expression was measured by real-time PCR using a LightCycler (Roche Diagnostics, Mannheim, Germany) instrument with the QuantiTect ${ }^{(i x)}$ SYBR Green PCR system (Qiagen K. K., Tokyo, Japan) starting with $1 \mathrm{ng}$ of reverse-transcribed total RNA. GAPDH expression was used as an internal control. The primer sequences for GAPDH amplification were forward primer; 5'-CACCCTCAAGATTGTCAGCA-3' and reverse primer; 5'-GGTCATAAGTCCCTCCACGA$3^{\prime}$. For quantification of the levels of resistin and GAPDH mRNA expression, roughly equivalent size of the PCR products (133 and $103 \mathrm{bp}$ ), primer length $(20 \mathrm{bp})$ and GC-contents of each primer (50-60\%) were selected, and PCR was performed under the following conditions: $95{ }^{\circ} \mathrm{C} \times 15 \mathrm{~min}, 60 \times\left(94{ }^{\circ} \mathrm{C} \times 15 \mathrm{sec}, 55^{\circ} \mathrm{C} \times 20 \mathrm{sec}\right.$, $\left.72{ }^{\circ} \mathrm{C} \times 12 \mathrm{sec}\right)$.

GLUT4 mRNA expression was measured with the use of gene-specific double-fluorescent-labeled probes, TaqMan Universal PCR Mix and a 7700 Sequence Detector (Applied Biosystems, Foster, CA, USA). FAM and VIC were used as the $5^{\prime}$-fluorescent reporters while TAMRA was added to the $3^{\prime}$ end as a quencher. Primer and probe sequences were GLUT4 forward primer; 5'-GGA CCGCGAATAGAAGAAAGAC-3', GLUT4 reverse primer; 5'-CAACTTCATCATCGG CATGG-3', GLUT4 probe; 5'-FAM-TAGGGACCCATAGCAT CCGCCACA-TAMRA-3', GAPDH forward primer; 5'-TGACCCCTTCATTGACCTTCA-3', GAPDH reverse primer; 5'-GCCTTGACTGTGCCGTTGA-3', and GAPDH probe; 5'-VIC-TTCCAGTATGATTCCA CCCACGGCA- TAMRA-3'. PCR was performed under the following conditions: $95^{\circ} \mathrm{C} \times 10 \mathrm{~min}, 45 \times$ $\left(94{ }^{\circ} \mathrm{C} \times 30 \mathrm{sec}, 59^{\circ} \mathrm{C} \times 30 \mathrm{sec}, 72^{\circ} \mathrm{C} \times 30 \mathrm{sec}\right)$.

\section{Insulin assay}

Venous blood samples were collected at 8:00 AM of the day of slaughter. Plasma was harvested from the blood samples and stored at $-20{ }^{\circ} \mathrm{C}$ for later determination of insulin. The plasma insulin concentrations were determined using a commercially available radioimmunoassay (RIA) kit (Eiken Chemical, Tokyo, Japan).

\section{Statistical analysis}

Results were expressed as means \pm S.E.M. and were analyzed by Student's $t$-test.

\section{Results}

Neither the bovine resistin gene nor cDNA have been registered in public databases, so we screened bovine ESTs having homology with human resistin cDNA. As a result 
(A)
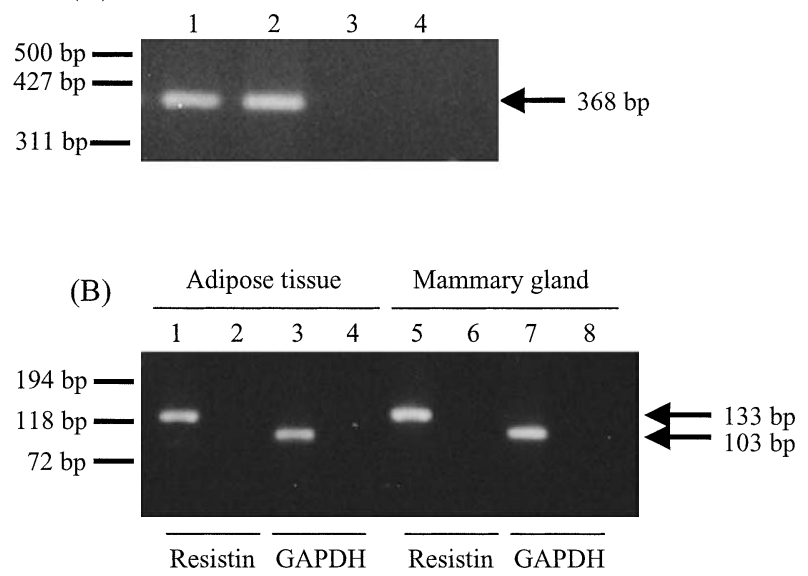

Figure 1 (A) Presence of resistin mRNA shown by RT-PCR. Lanes 1 and 3, bovine adipose tissue; lanes 2 and 4; mammary gland; lanes 3 and 4, no RT control. (B) Resistin and GAPDH amplicons by real time PCR. Lanes 2, 4, 6 and 8 were no RT controls. The total RNA was extracted from bovine adipose and mammary tissue, and reverse transcribed, and the product was amplified by PCR and then separated by agarose gel electrophoresis and detected with ethidium bromide staining.

of a BLAST search of the EST database with human resistin mRNA, a bovine EST (BM107148) of $478 \mathrm{bp}$ was identified. This bovine EST shared $83 \%$ sequence homology with human resistin cDNA, and contained the regions corresponding to exons $1,2,3$ and 4 , which together encode the entire open reading frame (ORF).

We designed RT-PCR primers based on the sequence of BM107148 and used them to obtain a single RT-PCR band using total RNA of adipose tissue (Fig. 1(A)). The sequence of this DNA fragment was the same as that of BM107148. From total RNA of the mammary gland, we also obtained an RT-PCR product of the predicted size (Fig. 1(B)).

Use of the QuantiTect ${ }^{(m)}$ SYBR Green PCR system at elevated temperatures resulted in reliable and sensitive quantification of the RT-PCR product with high linearity (Pearson correlation coefficient $r>0 \cdot 99$ ). Amplification of genomic DNA was avoided by designing primer pairs located in different exons, and therefore DNase treatment of tissue total RNA samples was unnecessary. Melting curve analysis revealed a single sharp melting point for bovine resistin at $83.5{ }^{\circ} \mathrm{C}$ and for bovine GAPDH at $82 \cdot 8{ }^{\circ} \mathrm{C}$ (data not shown).

The results of real-time PCR analysis showed that the expression of the resistin gene in adipose tissue was significantly higher $(P<0 \cdot 05)$ in lactating than nonlactating cows (Fig. 2(A)). In contrast, the expression of resistin in the mammary gland was significantly higher $(P<0 \cdot 05)$ in non-lactating than in lactating cows (Fig. 2(B)).
(A)

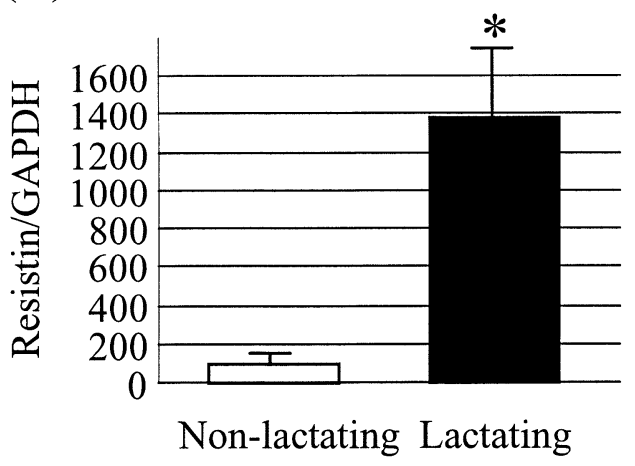

(B)

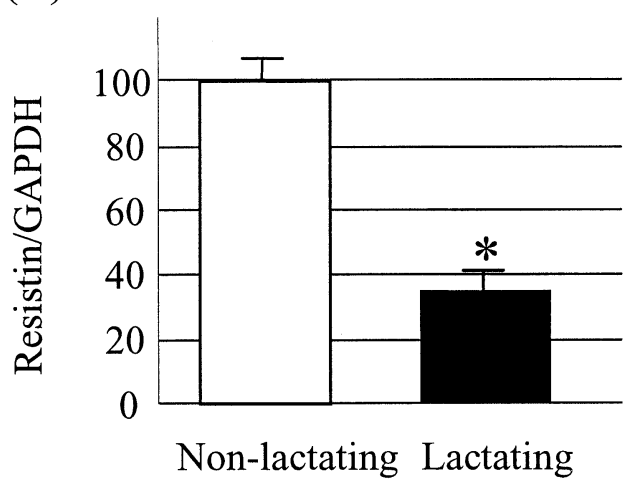

Figure 2 Resistin gene expression in adipose tissue (A) and mammary gland $(B)$ in non-lactating and lactating cows. Data are means \pm S.E.M. for 4 cows per group and expressed as the ratio of resistin mRNA relative to GAPDH mRNA (non-lactating $=100 \%$ ).

* Indicates a significant difference by Student's $t$-test at $P<0.05$.

There were no significant differences between the expression of GLUT4 mRNA in adipose tissue of lactating and non-lactating cows, and GLUT4 mRNA was not detected in the mammary gland of either lactating or non-lactating cows (Fig. 3).

The insulin concentration was significantly higher $(P<0 \cdot 05)$ in non-lactating than lactating cows (Fig. 4).

\section{Discussion}

In this study, our real-time PCR data showed that bovine adipose tissue expresses resistin mRNA, and that resistin mRNA expression increases in cows during the early phase of lactation. This is, to our knowledge, the first demonstration of resistin expression in bovine peripheral tissue. Cows at the peak of lactation show insulin resistance with respect to extramammary glucose utilization (Debras et al. 1989). We found no significant differences in the level of GLUT4 mRNA in the adipose tissue of lactating versus non-lactating cows. Intracellular GLUT4 was 


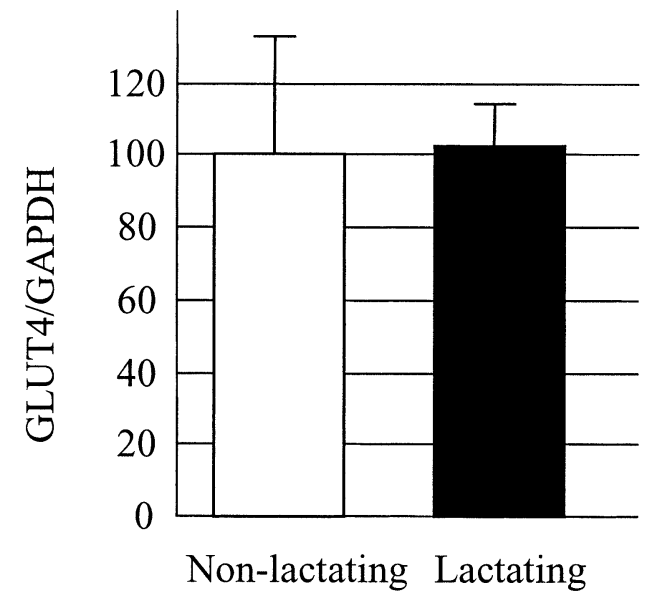

Figure 3 GLUT4 gene expression in adipose tissue in non-lactating and lactating cows. Data are means \pm S.E.M. for 4 cows per group and expressed as the ratio of GLUT4 mRNA relative to GAPDH mRNA (non-lactating $=100 \%$ ). GLUT4 mRNA was not detected in the mammary gland.

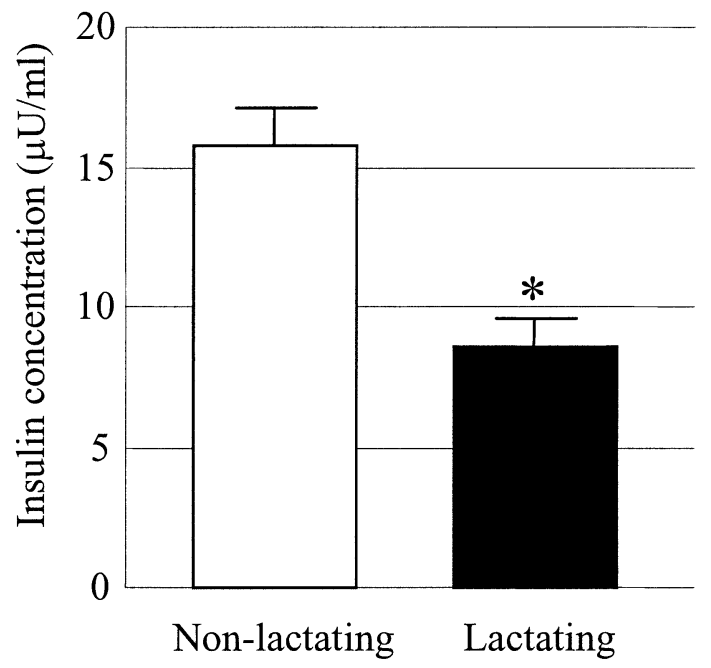

Figure 4 Plasma insulin concentration in non-lactating and lactating cows. Data are means \pm S.E.M. for 4 cows per group. * Indicates a significant difference by Student's $t$-test at $P<0.05$. Figure 1.

activated by insulin, and translocates to the cytomembrane. Since resistin secreted by adipose tissue increases insulin resistance in mice (Steppan et al. 2001), our findings suggest that the high resistin expression in bovine adipose tissue may contribute to the promotion of insulin resistance via inhibition of GLUT4 translocation to the cytomembrane, not GLUT4 expression, at lactation. It is also reported that in L6 cells, resistin was not affecting GLUT4 translocation and insulin receptor signaling (Moon et al. 2003). As they has considered, resistin may be inhibiting with insulin activation of the preexisting GLUT4 protein at the cytomembrane.
Lactation induces major metabolic adaptations accompanied by substantial changes in substrate flux; for instance, it causes a major loss of adipose tissue (Chilliard et al. 2000). The decrease of plasma insulin concentration at lactation may result in inhibition of the insulindependent glucose uptake in adipose tissue and muscle. It has also been suggested that resistin is an inhibitor of adipocyte differentiation (Kim et al. 2001). Therefore, in order to supply the substrate for milk synthesis to the mammary gland, adipocyte differentiation may be inhibited and insulin resistance may increase during lactation in cows. It has been reported that the resistin mRNA level in white fat tissue is unchanged while resistin-like molecules- $\alpha$ (RELM- $\alpha$ ) mRNA decreased in lactating mice (Bing et al. 2002). The function of RELM- $\alpha$ is largely unknown, and in bovine tissue, the expression of RELM- $\alpha$ is not investigated. Holsteins, in contrast to mice, are a breed of cattle bred for the improvement of milk production many generations. The changes of resistin expression in bovine adipose tissue and of the plasma insulin concentration we observed may be related to with the mass production of milk in these cows.

We also showed that resistin mRNA is expressed in the bovine mammary gland, and that this expression increases in no lactating cows. In the mammary gland, glucose is used for energy production and lactose synthesis. Although the mammary gland is insensitive to insulin during lactation (Laarveld et al. 1981), insulin is required for the proliferation and differentiation of bovine mammary epithelial cells (Cline et al. 1982). On the other hand, it has been reported that GLUT4 protein was not detected in the bovine mammary gland (Zhao et al. 1996), and we were not able to detect GLUT4 mRNA in the mammary gland. The production of resistin by the mammary gland suggests a possible role of resistin in regulating insulindependent glucose uptake in mammary epithelial cells. The decrease of resistin expression in the lactating mammary gland may serve to make the regulation of glucose uptake by insulin effective. Since GLUT4 was not detected in the mammary gland, a novel insulin dependent glucose transporter, for instance, GLUT12 (Macheda et al. 2003), may be involved in glucose uptake.

Based of these results, we propose that resistin has an important function in the adipose tissue and the mammary gland during lactation. This is the first report demonstrating a change in the expression of resistin in the mammary gland.

\section{References}

Bing C, Gomez Ambrosi J, Zabalegui N, Williams G \& Trayhurn P 2002 Resistin and RELM-alpha gene expression in white adipose tissue of lactating mice. Biochemical and Biophysical Research Communications 296 458-462.

Chilliard Y, Ferlay A, Faulconnier Y, Bonnet M, Rouel J \& Bocquier F 2000 Adipose tissue metabolism and its role in adaptations to undernutrition in ruminants. PNAS 59 127-134. 
Cline PR, Zamora PO \& Hosick HL 1982 Morphology and lactose synthesis in tissue culture of mammary alveoli isolated from lactating mice. In Vitro 18 694-702.

Debras E, Grizard J, Aina E, Tesseraud S, Champredon C \& Arnal M 1989 Insulin sensitivity and responsiveness during lactation and dry period in goats. American Journal of Physiology 256 E295-302.

Janke J, Engeli S, Gorzelniak K, Luft FC \& Sharma AM 2002 Resistin gene expression in human adipocytes is not related to insulin resistance. Obesity Research 10 1-5.

Kim KH, Lee K, Moon YS \& Sul HS 2001 A cysteine-rich adipose tissue-specific secretory factor inhibits adipocyte differentiation. Journal of Biological Chemistry 276 11252-11256.

Laarveld B, Christensen DA \& Brockman RP 1981 The effect of insulin on net metabolism of glucose and amino acids by the bovine mammary gland. Endocrinology 108 2217-2221.

Macheda ML, Williams ED, Best JD, Wlodek ME \& Rogers S 2003 Expression and localisation of GLUT1 and GLUT12 glucose transporters in the pregnant and lactating rat mammary gland. Cell and Tissue Research 311 91-97.

McDowell GH, Gooden JM, Leenanuruksa D, Jois M \& English AW 1987 Effects of exogenous growth hormone on milk production and nutrient uptake by muscle and mammary tissues of dairy cows in mid-lactation. Australian Journal of Biological Sciences 40 295-306.

Moon B, Kwan JJ, Duddy N, Sweeney G \& Begum N 2003 Resistin inhibits glucose uptake in L6 cells independently of changes in insulin signaling and GLUT4 translocation. American Journal of Physiology. Endcrinology and Metabolism 285 E106-E115.
Neville MC, Allen JC \& Watters C 1983 The mechanisms of milk secretion. In Lactation: Physiology, Nutrition, and Breast-Feeding, pp 49. Eds MC Neville and MR Neifert.

Rose MT, Obara Y, Itoh F, Hashimoto H \& Takahashi Y 1997 Non-insulin- and insulin-mediated glucose uptake in dairy cows. Journal of Dairy Research 64 341-353.

Steppan CM, Bailey ST, Bhat S, Brown EJ, Banerjee RR, Wright CM, Patel HR, Ahima RS \& Lazar MA 2001 The hormone resistin links obesity to diabetes. Nature 409 307-312.

Threadgold LC \& Kuhn NJ 1979 Glucose-6-phosphate hydrolysis by lactating rat mammary gland. International Journal of Biochemstry $\mathbf{1 0}$ 683-685.

Way JM, Gorgun CZ, Tong Q, Uysal KT, Brown KK, Harrington WW, Oliver WR Jr, Willson TM, Kliewer SA \& Hotamisligil GS 2001 Adipose tissue resistin expression is severely suppressed in obesity and stimulated by peroxisome proliferator-activated receptor gamma agonists. Journal of Biochemstry 276 25651-25653.

Zhao FQ, Dixon WT \& Kennelly JJ 1996 Localization and gene expression of glucose transporters in bovine mammary gland. Comparative biochemistry and physiology. Part B, Comparative biochemistry 115 127-134.

Received 26 June 2003

Accepted 6 August 2003

Made available online as an

Accepted Preprint 7 August 2003 